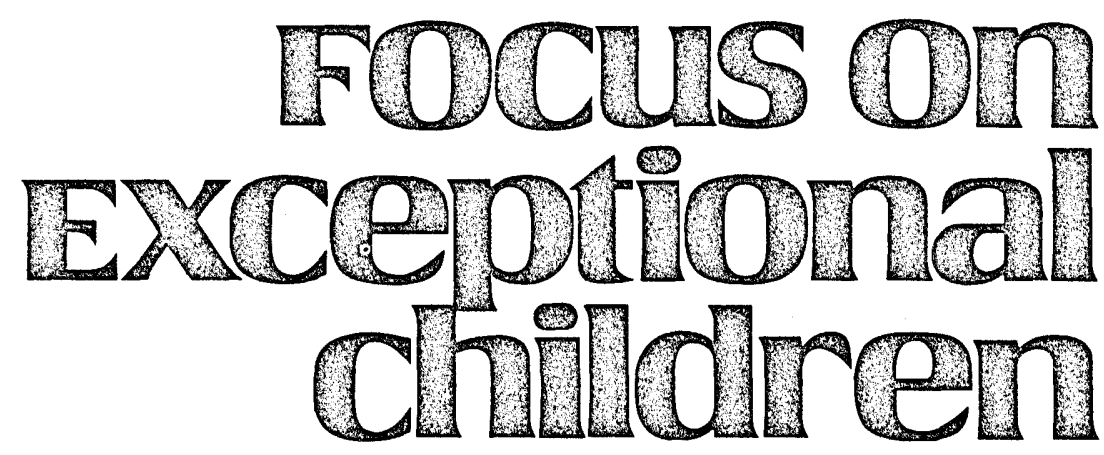

\title{
Individualizing Instruction With Microcomputer Software
}

\section{Louise S. Appell and Kathleen M. Hurley}

Long before there was a Public Law 94-142, many professional educators were aware that the diverse needs of handicapped learners required an approach, a strategy, and materials that would permit teachers to modify curriculum. Special children need special and different measures to help them reach their full potential. In 1965, a network of Special Education Instructional Materials Centers (SEIMCs) was established to help provide special educators with these tools. The federally funded SEIMCs stimulated developers and publishers to produce the material needed to provide teachers of handicapped learners with a wide range of choices to meet unique individual needs. For some students it was vocabulary builders; for others it was a lower rate of concept development; for still others it was adapted physical equipment or speech aids or high-interest, low-vocabulary readers or attention focusing games or multimedia presentations, and so on.

During the late 1960s and early 1970s special education grew rapidly when more children were identified as needing special instruction and special school placement. Increased awareness of handicapping conditions and better understanding of the potential for remediation contributed to this growth. New assessment tools, focusing on the particular deficit areas that hindered children from learning, were developed. Along with better assessment came better remediation tools. The discipline of special education became more sophisticated.

Louise Appell is a writer and curriculum developer affiliated with the professional services and applied research firm of Macro Systems, Inc., Silver Spring, Maryland. Kathleen Hurley is vice president of marketing and curriculum at Intentional Educations, Watertown, Massachusetts, and publisher of the monthly newsletter Micro Market Examiner. 
The Education for All Handicapped Children Act of 1975, Public Law 94-142, mandated that public schools make changes in assessment techniques, placement practices, and parental involvement, and that each child have an Individualized Educational Program (IEP). Despite the major developments that had been occurring in the years preceding this legislation, the IEP requirement was and is perceived by many teachers as an exciting challenge but a heavy burden. Requirements for curriculum modification, special materials, adaptive devices, and extensive record keeping have combined to create a host of problems associated with individualization of instruction.

\section{A NEW TECHNOLOGY FOR SCHOOLS}

When microcomputers came to school, special educators were among the first to recognize their potential worth as a resource for individualizing instruction. Gary Bitter, author of numerous books on computer literacy and acknowledged leader in educational uses of the computer,

\section{FOCus on
Exceptional children}

FOCUS ON EXCEPTIONAL CHILDREN (ISSN 0015-511X) (USPS 203-360) is published monthly except June, July, and August as a service to teachers, special educators, curriculum specialists, administrators, and those concerned with the special education of exceptional children. This journal is abstracted and indexed in Exceptional Child Education Resources, and is also available in microform from Xerox University Microfilms, Ann Arbor, Michigan. Subscription rates, $\$ 18.00$ per year. Copyright ${ }^{\odot}$ 1984, Love Publishing Company. All rights reserved. Reproduction in whole or part without written permission is prohibited. Printed in the United States of America. Second class postage is paid at Denver, Colorado. POSTMASTER: Send address changes to:

$$
\begin{aligned}
& \text { Love Publishing Company } \\
& \text { Executive and Editorial Office } \\
& 1777 \text { South Bellaire Street } \\
& \text { Denver, Colorado } 80222 \\
& \text { Telephone (303) } 757-2579
\end{aligned}
$$

\section{EDITORIAL BOARD}

\author{
Edward L. Meyen \\ University of Kansas \\ Glenn A. Vergason \\ Georgia State University \\ Richard J. Whelan \\ University of Kansas Medical Center
}

addressed the issue of computer acceptance in a speech at the Microcomputers in Special Education Conference in Hartford, Connecticut, in 1982. He indicated that special educators were more accepting of the computer in the classroom than were general educators, probably because of their flexibility in exploring new instructional options.

The willingness to use this new technology is, at least partially, related to the fact that human/machine interface systems have been used in this field for a long time. Primitive communication devices for the speech/language impaired were developed as early as the 1950s. Typewriters with special keyboards have allowed cerebral palsied students to prepare written work, and sonar devices have replaced the white cane for many visually impaired persons since the 1960s. Many special education teachers have used handmade "teaching machines" to present learning material in small increments, control the rate of presentation, and reinforce correct answers. These cardboard devices met a number of special needs and helped many, many children to learn, although they required enormous amounts of teacher preparation time.

Microcomputers in the nation's schools were initially used to perform administrative/management tasks. Gradually, teachers began to see them as tools and resources for instruction. In particular, special education teachers and administrators recognized the potential for using special software to monitor educational progress and to provide individualized, one-on-one instruction.

\section{THE MANY AND VARIED ROLES OF THE MICROCOMPUTER}

To derive the maximum benefit from microcomputers, one must examine a wide range of roles within the capability of existing technology. Certainly, there will be more to come. Like television before the VCR and telephones before the beeper, the challenge to further development will result in more sophistication and refinement. This article discusses the roles that microcomputers can play to enhance curriculum and instruction.

\section{Patient Teacher}

In basic skills work the computer is tireless, patient, nonjudgmental, and supportive. It can provide students with stress-free drill and practice, freeing the teacher for other tasks. It tends to stimulate curiosity, a major component in motivation to learn. Because special students often require much practice and repetition to master basic skills, this is an especially important role. 


\section{Accessible Laboratory}

Many different kinds of scientific experiments can be modeled on the microcomputer. It can provide simulation of conditions that would be too dangerous, costly, or impracticable otherwise. The educational opportunities for discovery learning are excellent. Where physically impaired students might never have access to some locations or conditions, the expanded access to scientific laboratories and restricted environments is a major role of the microcomputer.

\section{Responsive Instructor}

The interactive capabilities of the microcomputer are important in providing tutorial learning experiences for special students. These concept-building activities are enhanced by personalizing the presentation and by stimulation and reinforcement. Students are often less inhibited in their responses, more willing to stick to the task, and less fearful of making mistakes.

\section{Facilitator for Problem Solving}

The development of problem-solving skills has become critical to functioning well in the world today. Learning to think logically and creatively about complex events and relationships can be the key to vocational success. Data bases and rapid retrieval of information by the microcomputer make it an ideal tool for students to use in developing these essential skills.

\section{Demonstration Device}

Some concepts can be demonstrated with special clarity using the graphics feature of the microcomputer. For creating maps, charts, graphs and geometric figures, for demonstrating spatial relationships, and for illustrating consequences of some interaction, it has enormous instructional potential.

\section{Musical Instrument}

The value of the microcomputer's role in teaching composition and musical theory lies not only in its ability to produce a range of sounds and display the music on the screen. Not to be discounted are repetition, correction, reinforcement, and the absence of external pressure to perform. The microcomputer does not get headaches from wrong notes.

\section{Innovative Art Supplier}

The microcomputer can provide a blank drawing tablet, a stretched canvas, and the tools to create. The color and graphics features allow students to generate images, erase them, modify them, and even store them for later embellishment. For some students whose physical disabilities preclude the use of more traditional art supplies, this role of the microcomputer can be a wondrous thing indeed.

\section{Gameboard and Playing Field}

Games played on the computer are highly motivating and exciting to youngsters. Their value as an instructional aid lies in their ability to develop decision-making skills, increase attention span, improve coordination, and add a dimension of fun and gaiety to the classroom.

\section{Special Study Topic}

When you consider the ever-increasing use of the computer in business and industry, government, farming, research, and entertainment, it should be obvious that understanding the computer itself and how it works is becoming an essential area of knowledge. Special students, in particular, will need to be aware and informed about these power-packed devices if they are to compete in the economic marketplace. Unlike some earlier technologies that educators embraced and then discarded, this technology has roots firmly implanted in the world of work.

\section{Powerful Prosthesis}

With the addition of creative peripherals to the microcomputer, many physically impaired learners can communicate efficiently for the first time in their lives. Special keyboards, switches, light pens, touch-sensitive screens, voice recognition, speech synthesizers, adapted keyboard commands, and scanners can enable students with serious disabilities to function academically and socially as never before. The feelings of independence, self-worth, and access to a wider world are clearly enhanced when a student has the use of a microcomputer with specialized components.

\section{Manager}

The microcomputer is a whiz at record keeping, updating files, making lists, and scheduling. It is more 
efficient than any human at monitoring testing dates, retrieving file data, and cross-checking dates and places. Its word processing function is far better than any typewriter, and its use for accounting and budget analysis has been widely acknowledged. For any school system, it offers a major advantage; and for special education, it offers a particular advantage in its use for accomplishing a plethora of potentially onerous data management tasks. This role alone often justifies purchase.

\section{THE CRITICAL ISSUE OF SOFTWARE}

Despite the potential power of all these microcomputer roles, many special educators remain hesitant or even scornful. That may be because the microcomputer, much like television, is only as good as the programs available for it. The great flurry of activity in program development has resulted in an abundance of software or courseware, but much of it falls short of the mark. The federal Office of Technology assessment study on informational technology found widespread agreement that, with few exceptions, educational software is of poor quality. One reason cited was the paucity of curriculum experts qualified to produce software. In his report on microcomputer use in schools, Becker (1982) asserted:

\section{Two defects appear to predominate in current microcomp- uter software. First, most educational software is written in short, disconnected modules that are unrelated to one another and not clearly tied to other instructional activities or to specific textbooks. Second, most programs are boring and repetitious.}

Similarly, experts in microcomputer applications in special education lament the shortage of quality software for use in special education and point out the need for further research on how computer-assisted instruction can be used most effectively with students who are handicapped. Hofmeister (1982) has noted that on the whole, software has failed to build upon the significant advances that have been made in instructional theory and in hardware. Budoff and Hutton (1982) have attributed the lack of good software design, in part, to the lack of conclusive evidence about what features of computerassisted instruction do and do not "work" with different types of handicapped learners. A third factor commonly cited as the crux of the software problem is that most software developers focus on the iechnical aspects of the software, often to the exclusion of the educational aspects (Chandler, 1983).

Creating and producing quality educational software require large amounts of time and money. Few publishers have perceived the special education market to be big enough to risk investment in developing software especially for handicapped learners. At the same time, there is a genuine concern that teachers will not be critical enough in their choice of educational software to warrant the added expense of developing superior quality materials (Oids, 1981). Since many teachers are eager to explore the microcomputer's potential, they (or their school's procurement office) have been buying software that is available, even if it is not ideal. This only serves to further confirm the erroneous perception by commercial software publishers of an uncritical and undemanding audience.

\section{MAKING INFORMED CHOICES}

Every special educator interested in exploring the potential of the microcomputer as an instructional tool must become informed and pro-active in making choices for its use with special students.

\section{By reading the professional literature.}

Evidence that computer-assisted instruction results in increased academic achievement for certain handicapped learners is being reported (Hasselbring, 1982; Hallworth \& Brebner, 1980) even if it is fragmentary. Because the use of microcomputers in special education is a relatively new phenomenon, one can expect the literature in this area to be thin and elusive. Much of it is in the form of position papers, surveys on usage, and projections for the future. What there is, however, does seem to be positive. For example:

- A goal-based computerized management system within a reading software program by Stevenson, Edwards, and Bianchi was subjected to a 2-year validation study using 6,000 experimental and 10,000 control students. Students at all ability levels showed improvements (Hofmeister, 1982, p. 119).

- Propp, Nugent, and Stone in 1980 found that computers interfaced with videodiscs were successful for individualizing instruction with hearing impaired students. The Exceptional Child Center at Utah State University in Logan has been assessing the feasibility of Apple computer/videodisc applications with mentally retarded students. A range of retardation and curriculum were field tested. The results were positive, and the technology will be used in classrooms as soon as it becomes readily available (Hofmeister \& Thorkildsen, 1981, p. 37). 
- Lally (1981) reported appreciable improvement in the handwriting skills of learning disabled students who used a digitiser light pen in conjunction with a special display screen. He also reported both short-term and substantial gain for mentally retarded students who were taught sight word recognition via computer synthesized speech. He found similar learner gain in a unique study of computerbased learning environments for enhancing concept format in two areas: conservation of number, and basic spatial concepts.

- Watkins and Webb (1981) found that elementary-age learning disabled students who received computer-assisted instruction in mathematics achieved significantly greater post-test scores than did students who received more traditional special education math instruction.

- Susan Rose, at Ohio State University in Columbus, reported that 20 deaf students diagnosed as having multiple handicaps of mental retardation or learning disability did as well as nonhandicapped students in initial computer instruction, and surpassed hearing students in terms of following directions (Eversole, 1983, p. 10).

- Tawney developed an automated learning center for severely developmentally retarded and multiply handicapped preschoolers. Standard switches enabled students to interact with the computer using a point-touch response. Through the experiment, students were able to enter instructional programs in object recognition (Tawney \& Cartwright, 1981, p. 10).

- Apple microcomputers have been interfaced successfully with voice synthesizers to assist people who are blind. In 1981, Micro-Scope reported successful use of a speech training device that enables deaf people to see visual images of utterances. In 1982, MCE, Inc. field studies reported much success in using a commercially developed microcomputer program with autistic children (Taber, 1983, p. 81). The Apple II computer is interfaced with the videodisc as a main form of reading and language development at the California School for the Deaf. John Russell, Media Director at St. Mary's School for the Deaf in Buffalo, reported positive motivation and utilization factors of the Apple microcomputer with deaf students, including its ability to be programmed to meet specific school and student needs (Russell, 1982, p. 525).

- Reports from a Commack, New York, junior high resource room (Beckerman, 1983) attest to the way a microcomputer, printer, and simple word processing software can provide even the most severely expressive language-impaired students with successful writing experiences.

- For many handicapped youngsters, some of the most difficult objectives to achieve are those of written language skills. The tedium of organizing and reorganizing thoughts, writing them down, correcting errors, and seemingly endlessly recopying work is truly a barrier to writing. Word processing software provides a tool for saving time and energy that will allow the student to focus his or her energy on composition and expression (Hagen, 1983).

- Goldenberg's work (1979) with deaf, autistic, and severely physically handicapped children provides some of the earliest evidence of using the processing tool to motivate improved communication.

- Of all the benefits of microcomputer use, perhaps the most universally acknowledged is the microcomputer's power to engage and motivate special needs students. A Canadian study (Kleiman, Humphrey, \& Lindsay, 1981) reported that hyperactive children were willing to spend significantly more time working problems on the computer than working with paper and pencil. Children claimed that the math problems seemed much easier on the computer.

\section{By determining goals and objectives for its use.}

Before making a software purchase, one must know what goals and objectives for learners the software is expected to meet. Fitting the learner to the software is surely not appropriate, and yet some educators have been doing that. Not surprisingly, this strategy is doomed to failure.

If sound educational objectives are based on assessment results, it should follow that information is available about critical factors such as student reading level, language capability, math, and the like. These are important bits of information to use in making choices. A well developed list of characteristics and needs of the learners who will be using the software can be a valuable aid in choosing appropriate material.

\section{By studying the software reviews.}

Increasing numbers of computer periodicals are appearing in libraries and even at local newstands. Many school 
media and resource rooms have begun to subscribe to these popular magazines.

Most of these periodicals feature reviews of current and choice software by knowledgeable educators with experience in software development. One should keep in mind that some biases may be present in reviewers whose perspectives on the needs to be met with a particular software package could be colored by personal experience. Nevertheless, these reviews help the potential buyer in focusing on where to start a search for appropriate, welldesigned software. (See the Resources section at the end of this article for a list of popular computer magazines and special education journals that include software reviews.)

\section{By personally evaluating the software.}

Several clearinghouses and organizations have established various evaluation checklists, formats, guidelines, and strategies for determining the worth and validity of microcomputer software. Deciding which is suitable to use is, at least partly, a matter of individual preference. (See the Resources section for a list of clearinghouses and organizations that supply software reviews.)

\section{DEVELOPING/ADAPTING STUDENT-USE SOFTWARE}

According to a survey conducted by Electronic Learning magazine, $60 \%$ of teachers polled acquired their software commercially, through major educational publishers, microcomputer manufacturers, local distributors, or noncommercial publishers (each about $15 \%$ of the sales). The remaining $40 \%$, however, prefer to create their own software or to use programs developed by other teachers in their schools because of:

1) Dissatisfaction with commercially available software;

2) Frustration from not being able to review before buying; and

3) Satisfaction over the increased flexibility and control which writing one's own software allows. (Microcomputer Education Applications Network, 1983)

Although this can offer an exciting alternative for many people, the process is time-consuming and rather complicated. To enroll in a class at a local college or university or technical school may be wise. Some people have taught themselves how to program by studying one of the many books available, but this is probably less satisfactory than being in a class situation where questions can be answered and problems unraveled.

Several microcomputer authoring sytems have been developed specifically to enable educators to become authors of software. As teachers learn how to tell the computer what to do, a wide range of options becomes available for meeting particular learning needs. The amount of technical sophistication required by the educator-programmer to write or adapt instructional material is decreasing as new authoring systems are developed.

Designing and developing educational software is much like designing and developing any other type of instructional material. It requires knowledge of the topic area and the learning characteristics of the targeted user. It requires a high degree of comfort with the medium (in this case the microcomputer), and it requires a well-developed purpose for the materials to achieve.

Getting comfortable with the computer can be a rewarding, exciting, even exhilarating experience. Most school media centers, public libraries, and all computer stores have microcomputers available to people who want to gain experience with this technological resource.

\section{WRITING SOFTWARE}

Software can be written in two ways-by using an authoring tool or a programming language. Authoring tools are designed to help teachers write their own software. They are based on the idea that lessons contain similar formats-instruction, questions, answers, and so on. Authoring tools enable the teacher to transform his or her own unique lessons to software.

\section{Authoring Tools}

There are two types of authoring tools-authoring systems and authoring languages. An authoring system is a program that prompts the teacher to supply information such as the text (instructional) material, questions/answers, and the parameters of the lesson. PILOT (Programmed Instruction Learning Or Teaching) is an authoring language developed specifically for teachers who want to write their own software but don't have the programming prowess. PILOT, a simplification of BASIC, offers a great deal of assistance to authors of software lessons. It is much easier to learn than BASIC and, therefore, is a timesaver. The same program that could take about 10 hours to write in BASIC can be done in about 1 hour using PILOT.

Choice of an authoring tool is extremely important and should be dictated, at least partially, by the kind of activities envisioned for its use. Many authoring systems 
and languages are limited in sequencing and branching instruction levels and in allowing for a mechanism for users to be able to correct mistakes. Others are limited in their interfacing capabilities, thus restricting use by physically handicapped students. In addition, some suffer from limited graphic capabilities, which preclude using motivational techniques to reinforce students or draw attention to important information. Be careful not to purchase a screw driver when a drill is needed to do the job!

Since the type and brand of microcomputer that the software will run on governs the choice of authoring tool to use in developing software, one must have this information in hand. Single or dual disk drive, $32 \mathrm{~K}$ or $64 \mathrm{~K}$, display monitor in color or black and white, number of picture cells (pixels) - all these factors will govern what can be done, and should be known (and understood) before beginning to design. An array of different authoring systems and PILOT versions exists. Some are listed below. The producers of these products can be contacted to obtain more information.

\section{Some of the Commercially Available Authoring Systems}

Author I, Radio Shack Education Division, 1400 One Tandy Center, Fort Worth, TX 76102

The Author/The Author Plus, Phoenix Performance Systems, 64 Lake Zurich Dr., Lake Zurich, IL 60047

Blocks, California School for the Deaf, Computer Lab, 39350 Gallaudet Dr., Fremont, CA 94538

CAIWARE-2D/CAIWARE-3D, Fireside Computing, Inc., 5843 Montgomery Rd., Elkridge, MD 21227

Courseware Development System, Bell \& Howell Co., 7100 N. McCormick Rd., Chicago, IL 60645

Courseware Master Designer Series, Courseware, Inc., 10075 Carroll Canyon Rd., San Diego, CA 92131

Create Series, Hartley Courseware, Inc., 123 Bridge St., Dimondale, MI 48821

The Educator, Spectrum Training Corp., 18 Brown St., Salem, MA 01970

Eureka Learning System, Eiconics, Inc., 211 Cruz Alta Rd., P.O. Box 1207, Taos, NM 87571

Ghostwriter, Cavri Systems, Inc., 26 Trumball St., New Haven, CT 06511
The Instructor, BCD Associates, Inc., 5809 Southwest Fifth, Oklahoma City, OK 73128

The Learning System, Micro Lab, Skokie Valley Rd., Highland Park, IL 60035

The Linguist, Gessler Publishing Co., 900 Broadway, New York, NY 10003

Micro Tutor, Entelek, Dept. 1, Ward-Whidden House, The Hill, Portsmouth, NH 03801

MicroTutor II EZ Author, Author Plus Systems, Scandura Training Systems, Inc., 1249 Greentree Ln., Narbeth, PA 19072

Patient Professor, Educational Systems Software, 23720 El Toro Rd., El Toro, CA 92630

Skillcorp Authoring System (formerly AIDS), Skillcorp Software Inc., 1711 McGraw Ave., Irvine, CA 92714

Tutorial Learning System, Diversified Educational Enterprises, 725 Main St., Lafayette, IN 47901

VBLS, Sterling Swift, 7901 South I-35, Austin, TX 78744

ZES Authoring System, Avant-Garde Creations, P.O. Box 30160, Eugene, OR 97403

Versions of PILOT

APPILOT II, Muse Software, 347 N. Charles St., Baltimore, MD 21201

Apple PILOT, Apple Computer Co., 10260 Bandley Dr., Cupertino, CA 95014

Atari Pilot, Atari, Inc. Computer Division, P.O. Box 427, Sunnyvale, CA 94086

Color PILOT/TRS-80 Micro PILOT, Radio Shack Education Division, 1400 One Tandy Center, Fort Worth, TX 76102

E-Z PILOT, Teck Associates, P.O. Box 8732, White Bear Lake, MN 55110

Mark PILOT, Bell \& Howell Co., 7100 N. McCormick Rd., Chicago, IL 60645

\section{Programming Languages}

All computer programming languages have a basic similarity in that they are constructed using mathematical 
logical principles, are designed to permit building on simple structures to more complex ones, and are made up of commands that produce routines to accomplish programming tasks (Kelman, Burdick, Choate, Hannify, Richards, Roberts, Walters, \& Tornrose, 1983). Here is a list of some of the most popular and useful programming languages used for developing educational software. Other programming languages used in the field of education are APL, LISP, Smalltalk, Assembly, FORTRAN, and COBOL.

- BASIC (Beginners All-Purpose Symbolic Instruction Code) is the language most frequently used in the production of courseware. It was developed specifically for educational purposes as a simple language to teach programming and has spawned a number of variations. Although BASIC is easier to learn and to use in writing programs than assembly or machine languages or FORTRAN, it is still difficult. Using it to program a simple drill-and-practice lesson can be time consuming.

- Logo is a sophisticated language with tremendous power, yet is so simple to learn and to use that it is the computer language of choice for very young child ren. The language is used to direct a symbol, called a "turtle," to move about, creating pictures and geometric figures. Some of the versions available are listed with the software in the References section of this article.

- Pascal, named after Blaise Pascal, is another language that was designed to teach programming. It has become a desirable language because its data structures allow programs to run quicker and its structured programming allows programs to be shorter and, therefore, take up less space than in BASIC.

- $\mathrm{C}$ is a small and easy-to-learn language designed for "serious" programming. It is dependent on the UNIX operating system. Because of the projected growth in use of the UNIX system, C may become a popular language in software development.

\section{Special Education Programs (SEP) Contracts or Developing Authoring Tools}

In the fall of 1983, the U.S. Department of Education, Special Education Programs, awarded three contracts for projects to develop authoring tools. The projects, called Microcomputer Software for Individually Managed Instruction, are described below.
- The Johns Hopkins University-Applied Physics Laboratory, 34th \& Charles St., Baltimore, MD 21218 (Paul L. Hazan, Project Director). This project will develop and evaluate an authoring system for teachers of handicapped children to use in producing individualized instruction, applicable to wide range of handicaps and requiring no programming knowledge by the teacher or major new equipment by the schools.

- Denver Research Institute-University of Denver, Denver, CO 80210 (Joseph P. Lamos, Project Director). This project will develop a two-level authoring system for individually managed instruction of the handicapped. A prototype model of the authoring system will permit two levels of authoring activity. The first level of activity will involve the production of "Micro-units" of instructional content. The development of these micro-units would occur by development groups within a school district or by commercial publishers. The second level of authoring would occur in the classroom by teachers. The second level of capability will allow the teacher to selectively combine micro-units to meet the needs of individual students. Micro-units will be authored to meet the instructional requirements for particular types of disability.

- Kent State University, Department of Special Education, 401 White Hall, Kent, OH 44242 (Robert A. Zuckerman, Project Director). This project will develop an authoring system allowing teachers with little or no computer programming skills to develop courseware for computer-assisted instruction of handicapped students. The project will adapt and modify an existing authoring system (Torricelli). The courseware developed under this authoring sytem will be selectable in terms of readability level, and the teacher will be able to select input and output modes for the lesson. This feature will allow handicapped students with the same instructional content needs to use the same courseware with a variety of input and output devices.

Despite all of this activity in developing a variety of authoring tools, it may be well to ponder the words of Herbert Kohn (Bradley, 1983): "I think that the LogoBASIC debate is like the Latin-Greek debate in the Middle Ages; when all other languages were changing and no one was going to speak Latin or Greek ... most of the languages are going to be obsolete very soon anyway" ( $p$. 28). For the foreseeable future, and until that lucky day comes along, you will need to make a choice from what is 
available as an authoring tool.

\section{THE DESIGN STEP/HURDLE}

Leave aside the consideration of expense in time and money. Many people spend a small fortune on interests such as cameras and photography. Do recognize, however, that time and money are required.

Well over half the task is similar to any other instructional materials design. Planning is essential. Objectives for learners must be defined. A design document must be prepared.

Depending upon what is to be accomplished, a strategy must be defined. Drill-and-practice software is the easiest to create but is frequently criticized for using the microcomputer to accomplish paper-and-pencil tasks. Some careful thought will be required to circumvent that trap. Tutorial dialogue is a concept-building, interactive type of computer lesson that takes more sophistication and programming knowledge to create. Simulations and games are less popular types of educator-developed software because they generally require more time and effort than individuals are willing to give.

In creating software, consider working with a team. Combinations of people that include some with content knowledge and some with technical computer skills are most advantageous. The tasks can then be spread around, and the collective input will enhance the total outcome.

The task of adapting existing software to meet the needs of handicapped learners can yield very satisfying results. Before beginning to design a new software program, you might look into commercially available software with the adaptation possibilities in mind.

Some manuals are available giving detailed guidance to those interested in creating software/courseware. Two of these are:

\section{Designing Instructional Computing Materials Minnesota Educational Computing Consortium 2520 Broadway Dr.}

St. Paul, MN 55113

\section{Author's Guide}

H.J. Peters and J.W. Johnson

CONDUIT

P.O. Box 388

Iowa City, IA 52244

\section{SOMETHING TO PONDER}

In his prognostications of the future, Toffler (1980) used the word "de-massification" to describe a growing focus on increased options in education, business, and industry. This is exactly the same concept as that implied by special education's keyword, "individualization."

In the early days of widespread public education for handicapped learners, the central issue was finding strategies that would work to ameliorate handicapping conditions and maximize potential. It became evident that each student is unique and that no one strategy is best. When an educational plan is based on individual multidimensional assessment and tailored to meet those individual needs, handicapped learners have their best chance for success. The microcomputer has capabilities right now that can help to effect the goal of individualization of instruction. In the future, even more individualization capabilities can be expected.

The march forward into the information age has been a steady path from one communication device to anothertelegraph ... telephone ... radio ... television. (No school children today even remember life before television!) What comes next can only be conjectured.

Enhancing the brain's power is clearly a reasonable expectation (Toffler, 1980). What this will mean for the language impaired and learning disabled could change entirely the way these people learn and interact with the world.

Computerized body parts are already available on an experimental or developmental basis. In years to come a dramatic improvement may come about in visual or hearing or orthopedic prostheses.

Access to learning through computers in homes and in public places may be already changing the way we think, and will behave in the future, about the role of schools in the lives of students. In the computer's ability to individualize all education, Naisbitt (1982) sees the answer to the decline of excellence in education.

The microcomputer does represent radical change, and such changes often generate fear and resistance. Some of these concerns relate to loss of control to machines, potential losses of positions and the isolating effects of relating to a screen rather than to a person. Many educators will need training and experience to deal effectively with those anxieties.

Nevertheless, the metamorphosis that has occurred in special education within the past 10 years has been met positively by most professionals. These educators have generally aligned themselves with the field and are flexible to new ideas, open to exploring new options, and earnestly seeking the best possible solutions for special students. 


\section{RESOURCES ${ }^{1}$}

\section{Software}

Publisher

BIPACS, 33 W. Walnut St., Long Beach, NY 11561

Bolt, Beranek \& Newman, 50 Moulton St., Cambridge, MA 02138

Britannica Computer-Based Learning, 425 N. Michigan Ave., Chicago, IL 60611

Cross Educational Software, P.O. Box 1536, Ruston, LA 71270

"Don't Ask" Computer Software, 2265 Westwood Blvd., Los Angeles, CA 90064

Edmark Associates, P.O. Box 3903, Bellevue, WA 98009

Ginn and Co., 191 Spring St., Lexington, MA 02173

Minnesota Educational Computer Consortium, 2520 Broadway Dr., St. Paul, MN 55113

Raised Dot Computing, 310 S. 7th St., Lewisburg, PA 17837

Rocky Mountain Software, 1028 Hamilton St., Vancouver, BC V6B 2R9

Scholastic, Inc., 902 Sylvan Ave., Englewood Cliffs, NJ 07632

School \& Home Courseware, 1341 Bulldog Ln., Suite C, Fresno, CA 93710

Software Research Corp., University of Victoria, P.O. Box 1700, Discovery Park, Victoria, BC V8W 2 Y2

Spinnaker Software, 215 First St., Cambridge, MA 02142

Synergistic Software, 830 N. Riverside Dr., Renton, WA 98055

\section{Math Software}

Conduit, P.O. Box 388, Iowa City, IA 52244

Control Data, P.O. Box 261127, San Diego, CA 92126

DLM, 1 DLM Park, Allen, TX 75002

\author{
Software \\ CALL (Computer Aided Language \\ Learning)
}

Story Maker

CARIS

Peachy Writer

SAM

Edmark Reading

Suspect Sentences

Spelling

Braille-Edit

Numbers (Braille)

Handicapped Typewriter

Bank Street Writer

Talking/Screen Textwriter

Visible Speech for Hearing Improvement

Story Machine

The Linguist

Green Globs

Darts

Academic Skill Builders
Use

A drill-and-practice program that emphasizes pronunciation, reading, spelling, grammar, vocabulary, and fluency

Reading and writing activity for elementary through high school

Uses animated cartoons to introduce reading and spelling of initial vocabulary

Text editor that provides large, doublesized text on the screen

Speech synthesizer, capable of producing speech, with unlimited vocabulary and fully adjustable pitch and rate

Beginning reading and language development program for non-readers

Employs a game format in which participants attempt to identify forged passages in professionảlly written work

Drills handicapped students on frequently misspelled primary and intermediate words

Word processing system combining editing in print, voice, and braille

Text and math equations entered from a braille device, printed in English

Useful for severely physically handicapped

Word-processor designed for youngsters grades 4-12

Combines a word processing program with a speech synthesizer

Designed for speech training, graphically displays pitch, rhythm, and amplitude in response to speech signals

Children create short stories. Program generates a cartoon depicting meaning of each sentence formed

Foreign language translation and tutorial software

Globs are scattered randomly on a graph and students try to destroy the globs by typing in appropriate equations

Teaches fractions; balloons appear on a number line and student guesses the value by trying to shoot at the balloon

A six-program series to reinforce basic skills. They are all drill-and-practice programs set in an arcade style format

'We thank Intentional Educations, Watertown, Massachusetts, for allowing us to use their resources data base to compile the following listing of software, periodicals, and organizations. 
Love Publishing Co., 1777 S. Bellaire St., Denver CO 80222

MCE, Inc., 157 S. Kalamazoo Mall, Kalamazoo, MI 49007
Software for Basic Math Skills

Job Readiness

Income Meets Expenses

You Can Bank On It

Money Management Assessment

Home Safe Home

Poison Proof Your Home

SpecialWare Directory

LINC, 1875 Morse Rd., Columbus, OH 43229

Prentke Romich Co., 8769 Turnpike Rd. 513, Shreve, OH 44676

Sterling Swift, 7901 S. 1-35, Austin, TX 78744

Trace Research and Development Center for the Severely Handicapped

\section{Software Review Sources}

Applesauce, P.O. Box 598, Venice, CA 90291

BYTE, 70 Main St., Peterborough, NH 03458

Call-A.P.P.LE., Apple Puget Sound Program, Library Exchange, 304 Main Ave. S., Suite 300, Renton, WA 98055

Classroom Computer Learning, 19 Davis Dr., Belmont, CA 94002

Compute!, 515 Abbott Dr., Broomall, PA 190908

Computing Teacher, Dept. of Computer and Information Science, University of Oregon, Eugene, OR 97403

Creative Computing, P.O. Box 789-M, Morristown, NJ 07960

\section{C.U.E. Newsletter, P.O. Box 18457, San Jose, CA 95158 \\ Educational Computer Magazine, P.O. Box 535, Cupertino, CA 95015 \\ 80 Microcomputing, 80 Pine St., Peterborough, NH 03458 \\ Electronic Classroom, 150 West Carob St., Compton, CA 90220 \\ Electronic Education, Electronic \\ Communications, Inc., Suite 200, 1311 \\ Executive Center Dr., Tallahassee, FL 32301}

Electronic Learning, Scholastic Inc., 902 Sylvan Ave., P.O. Box 2001, Englewood Cliffs, NJ 07632

Hardcore Computing, 14404 E.D. St., Tacoma, WA 98445
A system that pinpoints specific problem areas in fundamental math operations and provides practice based on individual needs; space graphics.
Lists instructional, administrative, professional, and evaluation/testing software for special education

Catalog available listing computer aids for the handicapped

Catalog with computer aids for the handicapped

Contains a section devoted to software for special needs

Contains systems and programs that have been written or adapted for the handicapped

Interface Age, 16704 Marquardt Ave. Cerritos, CA 90701

Journal of Computers in Mathematics and Science Technology, 1331 E.

Thunderhead Dr., Tucson, AZ 85718

Kilobaud Microcomputing, 80 Pine St., Peterborough, NH 03458

Microcomputer Digest, 103 Bridge Ave., Bay Head, NJ 08742

Nibble, P.O. Box 325, Lincoln, MA 01773

Personal Computing, P.O. Box 1408, Riverton, NJ 08077

Popular Computing, 70 Main St., Peterborough, NH 03458

T.H.E. Journal, P.O. Box 992, Acton, MA 01720

\section{Special Education and Technology Periodicals}

The Catalyst, Western Center for Microcomputers in Special Education, 1259 El Camino Real, Suite 275, Menlo Park, CA 94025

Closing the Gap, Route 2, Box 39, Henderson, MN 56004

Communication Outlook, Artificial Language Laboratory, Computer Science Department, Michigan State University, East Lansing, MI 48824
Focus on Exceptional Children, Love Publishing Co., 1777 S. Bellaire St., Denver, CO 80222

International Review of Special Education Technology, Counterpoint Communications Co., $750 \mathrm{McD}$ Donald Dr., Reno, NV 89503

Journal of Educational Technology Systems, Society for Applied Learning Technology, Baywood Publishing Co.,
120 Marine St., Box D, Farmingdale, NY 11735

Journal of Learning Disabilities, 1331 E. Thunderhead Dr., Tucson, AZ 85718

Journal of Special Education Technology, Exceptional Child Center, UMC-68, Utah State University, Logan, UT 84322

Update, LINC Resources, Inc., 1875 Morse Rd., Suite 225, Columbus, OH 43229 


\section{Clearinghouses and Organizations}

CONDUIT, 100 Lindquist Center, University of lowa, P.O. Box 388, lowa City, IA 52244 (319/353-5789)

Courseware Report Card, Educational Insights, Inc., $150 \mathrm{~W}$. Carob St., Compton, CA 90220 (213!637-2131)

Digest of Software Reviews: Education, 1341 Bulldog Ln., Suite C9, Fresno, CA 93710

EPIE Institute, P.O. Box 620, Stony Brook, NY 11790 (212/678-3340)

MEAN (Microcomputer Education Applications Network), Education
TURNKEY Systems, $256 \mathrm{~N}$. Washington St., Falls Church, VA 22046 (703/536-2310)

MicroSIFT, Northwest Regional Educational Laboratory, 300 S.W. Sixth Ave., Portland, OR 97204 (503/248-6800)

Minnesota Educational Computing Consortium, Instructional Systems Development, 2520 Broadway Dr., St. Paul, MN $55 I 13$ (612/638-0600)

National Council of Teachers of Mathematics (NCTM), 1906 Association Dr., Reston, VA 20091
School Micro Ware Publishers, $\mathrm{c} / \mathrm{o}$ Dresden Associates, P.O. Box 246, Dresden, ME 04342 (207/737-4466)

SECTOR: Special Education Computer Technology On-line Resources, Utah State University, Logan, UT 84332

SOFTSWAP, San Mateo County Office of Education, 333 Main St., Redwood City, CA $94063(415 / 363-5470)$

SpecialNet, National Association of State Directors of Special Education, 120116th St. N.W., Suite 610E, Washington, DC $20036(202 / 822-7933)$

\section{REFERENCES}

Becker, H. Microcomputers in the classroom: Dreams and realities (Report No. 319). Baltimore: Johns Hopkins University, 1982.

Beckerman, J. You don't have to know the language. Computing Teacher, 1983, 10, 23-27.

Bradley, B. Machines don't dehumanize, people do. Classroom Computer Learning, Sept. 1983.

Budoff, M., \& Hutton, L.R. Microcomputers in special education: Promises and pitfalls. Exceptional Children, Oct. 1982, pp. 123-128.

Chandler, $H$. If we're really on our way, shouldn't we use a roadmap? Journal of Learning Disabilities, 1983, 16, 54-56.

Eversole, C. Speaking the language of the deaf. Quest, 1983, 5(4), 10-11.

Goldenberg, E.P. Special technology for special children. Baltimore: University Park Press, 1979.

Hagen, D. Word processing: A powerful tool. Timely TIES Topics on Instructional Services, 1983, 11, 4-5.

Hallworth, H., \& Brebner, A. A multimedia CAI terminal based upon a microprocessor with applications for handicapped. Paper presented at annual convention, AEDS, St. Louis, April 1980.

Hasselbring, T. Remediating spelling problems of learning-handicapped students through the use of microcomputers. Educational Technology, 1982, 22, 31-32.

Hofmeister, A.M. Microcomputers in perspective. Exceptional Children, Oct. 1982, pp. 115-121.

Hofmeister, A.M., \& Thorkildsen, R.J. Videodisc technology and the preparation of special education teachers. Teacher Education \& Special Education, 1981, 4(3), 34-39.

Kelman, P., Burdick, A., Choate, J., Hannify, G., Richards, J., Roberts, N., Walters, J., \& Tornrose, M.K. Reading, MA: Addison-Wesley; 1983.

Kleiman, G., Humphrey, M., \& Lindsay, P. Microcomputers and hyperactive children. Creative Computing, 1981, 7, 93-94.

Lally, M. Computer-assisted instruction for the development of basic skills with intellectually handicapped children. Canberra, Australia: Australian Education Research and Development Committee, 1981.
Microcomputer Education Applications Network. The most popular software may be your own. Mean Brief Quarterly, January-March, 1983, p. 1.

Naisbitt, J. Megatrends. New York: Warner Books, 1982.

Olds, H.F. How to think about computers. Computer Technology Conference, Jan. 12, 1981.

Russell, J.W. The Apple microcomputer in school learning centers. Annals of the Deaf, 1982, 127(5), 522-526.

Taber, F.M. Microcomputers in special education. Reston, VA: Council for Exceptional Children, 1983.

Tawney, J.W., \& Cartwright, G.P. Teaching in a technology oriented society. Teacher Education \& Special Education, 1981, 4(3), 3-13.

Toffler, A. The third wave. New York: William Morrow \& Co., 1980.

Watkins, M., \& Webb, C. Computer assisted instruction with learning disabled students. Educational Computer Magazine, 1981, 1, 24-27.

\section{ADDITIONAL REFERENCES}

Carter, R. Beware of checklists! Classroom Computer News, 1983, 3, 74.

International Council of Administrators of Special Education. Computer use in special education administration survey. Reston, VA: Council for Exceptional Children, 1982.

Kurland, D.M. Software for the classroom: Issues in the design of effective software tools. In Chameleon in the classroom: Developing roles for computers (Technical Report No. 22). New York: Bank Street College of Education, 1983.

Online: Potential and pitfalls. Journal of Learning Disabilities, 1983, 16, 58-59.

Quality Education Data, Inc. Microcomputer buyers update. Denver, CO: QED, Feb. 1983.

Sheingold, K. Issues related to the implementation of computer technology in schools: A cross-sectional study. Paper presented at the National Institute of Educational Conference on Issues Related to the Implementation of Computer Technology in Schools, Washington, DC, 1981. 